Int J Obes (Lond). 2007 January ; 31(1): 131-137. doi:10.1038/sj.ijo.0803353.

\title{
Energy expenditure of genuine laughter
}

\author{
MS Buchowski $^{1,4}$, KM Majchrzak $^{1}$, K Blomquist $^{2}$, KY Chen $^{1}$, DW Byrne ${ }^{1,3}$, and J-A \\ Bachorowski $^{2}$ \\ ${ }^{1}$ Department of Medicine, Vanderbilt University, Nashville, TN, USA \\ ${ }^{2}$ Department of Psychology, Vanderbilt University, Nashville, TN, USA \\ ${ }^{3}$ Department of Statistics, Vanderbilt University, Nashville, TN, USA \\ ${ }^{4}$ Department of Family and Community Medicine, Meharry Medical College, Nashville, TN, USA
}

\begin{abstract}
Objective-To measure energy expenditure (EE) and heart rate (HR) during genuine laughter.

Design-Experimental trial of viewing film clips in four cycles either intended to evoke laughter (humorous $-10 \mathrm{~min}$ ) or unlikely to elicit laughter (not humorous $-5 \mathrm{~min}$ ) under strictly controlled conditions of a whole-room indirect calorimeter equipped with audio recording system.
\end{abstract}

Participants-Forty five adult friend dyads in either same-sex male $(n=7)$, same-sex female $(n=21)$ and mix-sex male-female ( $n=17)$; age 18-34 years; body mass index 24.7 \pm 4.9 (range 17.941.1).

Measurements-Energy expenditure in a whole-room indirect calorimeter, HR using Polar HR monitor. Laugh rate, duration and type from digitized audio data using a computerized system and synchronized with HR and EE results.

Results-Laughter EE was $0.79 \pm 1.30 \mathrm{~kJ} / \mathrm{min}(0.19 \pm 0.31 \mathrm{kcal} / \mathrm{min})$ higher than resting EE $(P<0.001,95 \%$ confidence interval $=0.75-0.88 \mathrm{~kJ} / \mathrm{min})$, ranging from -2.52 to $9.67 \mathrm{~kJ} / \mathrm{min}(-0.60$ $2.31 \mathrm{kcal} / \mathrm{min})$. Heart rate during laughter segments increased above resting by $2.1 \pm 3.8 \mathrm{beats} / \mathrm{min}$, ranging from -7.6 to 26.8 beats/min. Laughter EE was correlated with $\mathrm{HR}\left(I^{s}=0.250, P<0.01\right)$. Both laughter EE and HR were positively correlated with laughter duration $\left(r^{\mathrm{s}}=0.282\right.$ and 0.337 , both $P<0.001)$ and rate $\left(\mathrm{r}^{\mathrm{s}}=0.256\right.$ and 0.298 , both $\left.P<0.001\right)$.

Conclusion-Genuine voiced laughter causes a 10-20\% increase in EE and HR above resting values, which means that $10-15$ min of laughter per day could increase total EE by $40-170 \mathrm{~kJ}$ $(10-40 \mathrm{kcal})$.

\section{Keywords}

energy expenditure; heart rate; laughter; laugh rate and duration; adults; indirect calorimetry

\section{Introduction}

Laughter is a uniquely human vocal signal with possible health benefits attributed to reduced muscle tension, increased oxygenation of blood and exercising of the heart. The sounds of laughter are short, spasmodic and broken, and as Darwin observed, 'as different as possible

(C) 2007 Nature Publishing Group All rights reserved

Correspondence: Professor MS Buchowski, Department of Family and Community Medicine, Center for Nutrition, Meharry Medical College, 1005 D.B. Todd Blvd., Nashville, TN 37208, USA. maciej.buchowski@ vanderbilt.edu. 
from screams or cries. ${ }^{1}$ They are produced by contractions of the chest walls, and especially the diaphragm, forcing air through the vocal tract and often followed by a deep inspiration of air. ${ }^{2,3}$ Smiling and laughing may occur spontaneously in response to humor or to appropriate emotional or sociological stimuli, and can be elicited upon command as either a voluntary or contrived (fake) laughter. These two types of laughter involve different neural pathways. ${ }^{4}$

Clinical manifestations and putative neurological pathways of laughter have been described, but the presumed physiological changes accompanying laughter, including energy cost, have not.

Despite inconclusive evidence, ${ }^{5}$ the idea that laughter has positive health benefits has been attributed to changes in musculoskeletal, cardiovascular, endocrine, immunological and/or neural systems such as reduced muscle tension, increased oxygenation of blood, exercising of the heart and endorphins production. ${ }^{6,7}$ More specific effects of laughter include improved postprandial glucose transfer in the presence of insufficient insulin action in type 2 diabetic patients, ${ }^{8}$ increased leptin concentration in breast milk ${ }^{9}$ and cardioprotection. ${ }^{10}$

Elevated heart rate (HR) and muscle movements observed during laughter would suggest a possibility of increased energy expenditure (EE). However, to date there is no information available about whether the energy cost associated with laugh production is clinically significant. Thus, the objective of this study was to measure EE during laughter production. The null hypothesis was that energy expended during episodes of laughter would not differ significantly from energy expended during rest. To test this hypothesis, we measured the EE and HR in 45 sameor mixed-sex dyads of young men and women during viewing film clips designed to evoke either laughter or a more neutral response.

Participants were tested in dyads composed of friend pairs because laughter is far more likely to occur in social contexts and, furthermore, more likely to occur among friends than among strangers. ${ }^{11}$ Same- and mixed-sex dyads were assembled mainly out of convenience: interested participants were simply asked to bring a friend of either sex to the testing site. The social context of the testing environment was therefore one that was conducive to eliciting laughter. Participants, however, were unaware that laughter was the focus of the study. The study was conducted in the strictly controlled environment of a whole-room indirect calorimeter equipped with an acoustic recording system. We assumed that if the null hypothesis was not supported, our experimental data would be sufficient to calculate the energy cost associated with laugh production and to assess its clinical significance by comparing with other types of miscellaneous daily activities.

\section{Materials and methods}

\section{Participants}

Thirty-one males and 63 females aged 18-34 years were recruited to participate in this study in either same-sex male (M-M), $n=7$, same-sex female (F-F), $n=21$ and mix-sex malefemale (M-F), $n=17$, friend dyads. As the audio recordings from two dyads (F-F) could not be analyzed, these data were excluded from further analyses. Participant characteristics are shown in Table 1. The study was approved by the Institutional Review Board of Vanderbilt University, Nashville, TN, USA. Each participant provided written consent before the study and was fully debriefed after participation.

\section{Study protocol}

Study participants were scheduled in dyads for testing at the General Clinical Research Center at Vanderbilt University. To ensure that laughter was genuine and not biased by 
experiment objectives, participants were told that the purpose of the study was to rate their emotional reactions to a variety of film clips while simultaneously measuring their resting $\mathrm{EE}$ and HR. Each pair was brought to the room calorimeter and seated in lounge chairs that faced the television set. They were asked to wear a wireless microphone transmitting audio data to corresponding receivers in the adjacent room. To minimize bias, participants were told that the purpose for wearing the microphones was to obtain a taped record of their emotional ratings of each film clip. Participants were given a rating sheet to use as a guide for oral (audio taped) ratings for each film clip. Ratings of film clips included numerical ratings of valence on a scale from one (completely negative) to nine (completely positive) and intensity on a scale from one (completely relaxed) to nine (completely excited).

Participants were asked to choose from a list of emotion words that best described how the film clip made them feel. Data from the questionnaire were not intended to be analyzed. Audio digital signals were recorded separately for each participant. Participants also wore a HR monitor. They were instructed to sit passively and not talk with one another during the session. Participants sat in a reclining position, acclimated to the room calorimeter for approximately $10 \mathrm{~min}$, and then were asked to start the video using a remote control. For 90 min, each pair viewed a series of film clips selected to evoke either a laughing response or a neutral response. The videotape began with a 30-min segment on England's landscape during which resting EE was measured. The following series of four segments consisted of a 10-min film clip explicitly intended to evoke laughter (humorous) and a 5-min clip of a documentary that was unlikely to elicit laughter (not-humorous) allowing EE and HR to return to resting levels. During the 90-min viewing of film clips, participants' audio data were recorded. After viewing the tape, participants remained in the room calorimeter for approximately $10 \mathrm{~min}$. Debriefing at the end of the test session included disclosure that laughter was a central focus of the investigation. Participants were then asked to provide written consent for the use of their laughter data. After exiting the room calorimeter, body composition was measured. Participants were compensated with a small sum of money for taking part in the study.

\section{Measurements}

Energy expenditure-Total EE was measured in a whole-room indirect calorimeter, a small, airtight environmental room (19500 1 in net volume) equipped with a desk and two chairs, an outside window, telephone, a TV/VCR and an audio system. The research staff and participants can see each other through a glass window connected to an anteroom; communication occurs via an intercom.

Oxygen consumption $\left(\mathrm{VO}_{2}\right)$, carbon-dioxide production $\left(\mathrm{VCO}_{2}\right)$, air flow rate, temperature (inside and ambient), barometric pressure and humidity of the air are sampled 60 times per second and integrated at the end of each minute to calculate EE on a minute-by-minute basis. ${ }^{12}$ This accuracy of our system is $>90 \%$ within a minute and allows precise measurement of EE during short bouts of increase EE above the EE during rest. ${ }^{13}$

Resting energy expenditure-Resting EE ( $\mathrm{kcal} / \mathrm{min})$ was defined as the average baseline EE during a 30-min period of sitting in reclining position after the initial 10-min rest. As physical activity significantly elevates EE, periods of physical movement detected by a large precision force platform covering entire living space of a room calorimeter was subtracted from the REE calculation. ${ }^{13}$

Energy expenditure of laughter-Energy expenditure of laughter ( $\mathrm{kcal} / \mathrm{min}$ ) was defined as the EE above the resting EE spent by the participants during laughter episodes subsequently identified via acoustic analysis. 
Heart rate-Heart rate (beats/min) was measured at $5 \mathrm{~s}$ intervals with a HR monitor (Polar Vintage NV, Polar, Port Washington, NY, USA) consisting of a sensor/transmission chest band and receiver/storage wristwatch.

Anthropometric and body composition measurements-Body weight was measured to the nearest $0.05 \mathrm{~kg}$ with a digital scale. Height was measured to the nearest 1 $\mathrm{cm}$ with a beam-scale mounted stadiometer. Body mass index (BMI) was calculated as a ratio of body weight $(\mathrm{kg})$ to height $\left(\mathrm{m}^{2}\right)$.

Audio recording-A Tascam DAT-40 recorder (TAEC, Montebello, CA, USA) was used to record participants' vocal samples. During testing, each participant wore a head-worn wireless microphone (Audio-Technica 1400 series UHF, Audiotechnica, Stow, OH, USA) positioned about $10 \mathrm{~cm}$ below participants' lips. These microphones precluded amplitude shifts due a participant's head turning, did not record background noise, and allowed independent signals to be recorded for each participant.

Acoustical outcomes-Audio data recorded while participants viewed the 90-min video were later displayed on a micro-computer using Kay's Computerized Speech Lab (CSL; Lincoln Park, CA, USA). Individual laugh rate, duration and type (voiced, unvoiced and mixed) were assessed for each participant by trained research assistants who watched the digitized displays and simultaneously listened to the recordings via headphones (Beyerdynamic DT 250; Heilbronn, Germany). A laugh is characterized as a single laugh episode or utterance, usually involving one exhalation and/or inhalation. Laugh types were coded using CSL's waveform display to assess for evident periodicity in the signal. ${ }^{14}$

Data analysis-Participants were tested as dyads and their acoustical data and EE data were compared using the dyad as a single unit of measurement. Laughter rate was calculated as the number of single laugh episodes produced during a 1-min interval. Individual laugh durations were measured by identifying each laugh's beginning and end with cursors, and then recording the time for that interval from the waveform toolbar. The dyad's total laugh duration per minute was calculated by summing the individual laugh durations. Laugh rate and laugh duration for each 1-min interval was calculated for each dyad by summing across partners and dividing by 2. Laughter EE was defined as an increase in EE during laughter episodes above EE during rest. As EE was measured for the dyad, the result was divided by 2. Laughter HR was defined as an individual increase in HR during laughter episodes above HR during rest. Laughter EE, HR, duration and rate were matched on a minute-by-minute basis.

\section{Statistical analysis}

The sample size was calculated using data from pilot work showing that the difference in energy expenditure between resting and laughter was $0.14 \mathrm{kcal} / \mathrm{min}$. Using a two-sided $t$-test with $a$-level of 0.05 , we calculated that six pairs in each type of dyad group would provide 90\% statistical power to detect differences between resting EE and laughter EE within each group. The treatment (laughter vs non-laughter) was the within-subject measure. Statistical analysis of the data was performed using a general linear model. Differences between outcome variables in quartiles by laughter duration were assessed using the Kruskal-Wallis nonparametric test. Spearman's correlation coefficients were calculated between laughter indices and physiological response (EE and HR) to evaluate the effect of laughter duration and rate on laughter EE and HR. A $P$-value of less than 0.05 was considered statistically significant. Statistical analysis was performed using SPSS v.12 (SPSS Inc., Chicago, IL, USA). 


\section{Results}

There was a significant $(P<0.001)$ increase in EE and HR when participants viewed film clips selected to evoke laughter as compared to the rest period. A graphical illustration of simultaneous measurements of EE, HR and laughter duration in a randomly selected dyad is presented in Figure 1.

\section{Participants characteristic}

Participants were a heterogeneous group of young adults (18-34 years old) with a wide range of body weight $(41.1-138.7 \mathrm{~kg})$ and BMI $\left(17.0-41.1 \mathrm{~kg} / \mathrm{m}^{2}\right)$. Body weights in dyads were correlated (Figure 2). Men were taller and heavier than women $(P<0.001)$. These results are presented in Table 1.

\section{Laughter energy expenditure}

Average EE measured during laughter episodes was $5.53 \pm 0.63 \mathrm{~kJ} / \mathrm{min}(1.32 \pm 0.15 \mathrm{kcal} / \mathrm{min})$ and it was significantly higher $(P<0.001)$ than EE during the rest period $(5.11 \pm 0.71)$. Difference in EE between viewing humorous and non-humorous figlm clips are shown in Figure 2. Laughter EE was positively correlated with laughter duration $\left(I^{S}=0.282, P \unlhd 0.001\right)$ and laughter rate $\left(I^{s}=0.256, P \unlhd .001\right)$, independent of the viewed film clip. Average resting $\mathrm{EE}$, absolute laughter EE and percentage increase in EE during laughter are shown in Table 2. There was no significant difference between dyads laughter EE and the difference in body weight between individuals in each dyad (paired $t$-test, $P=0.094$ ). When divided into quartiles according to laughter duration, the highest laughter EE $0.84 \pm 0.84 \mathrm{~kJ} / \mathrm{min}$ $(0.22 \pm 0.20 \mathrm{kcal} / \mathrm{min})$ was in a quartile with laughter longer than $20 \mathrm{~s} / \mathrm{min}$. In the remaining quartiles (10-20, 5-10 and $<5 \mathrm{~s} / \mathrm{min})$, laughter EE was $0.68 \pm 0.76,0.49 \pm 0.63$ and $0.27 \pm 0.59$ $\mathrm{kJ} / \mathrm{min}$, respectively. Differences between the quartiles were significant $(P<0.001$, Figure 3$)$.

\section{Heart rate}

Absolute HR difference between the rest and laughter episodes was $2.15 \pm 3.80$ beats $/$ min $(P<0.001)$. Laughter HR was positively correlated with laughter duration $(r=0.337, P<0.001)$ and laughter rate $\left(I^{2}=0.298, P<0.001\right)$, independent of viewed film clip. The highest laughter HR (11.94 \pm 6.38 beats $/ \mathrm{min})$ was in a quartile with laughter longer than $20 \mathrm{~s} / \mathrm{min}$. In the remaining quartiles (10-20,5-10 and $<5 \mathrm{~s} / \mathrm{min})$, laughter $\mathrm{HR}$ was $5.59 \pm 4.81,3.23 \pm 3.75$ and $1.46 \pm 3.20$ beats/min, respectively (Figure 3 ). Differences between the quartiles were significant $(P<0.001)$.

\section{Laughter duration and rate}

Laughter duration was significantly correlated between individuals in dyads $(r=0.574$, $P<0.001)$ and the difference in the total time spent laughing was not significant $(P=0.899$, paired $t$-test). When viewing humorous segments, participants laughed on average $5.9 \pm 5.3 \mathrm{~s} /$ min, with the laughter time ranging from 0 to $40 \mathrm{~s} / \mathrm{min}$. Same-sex male dyads spent on average significantly $(P=0.002)$ more time laughing than mix-sex or same-sex female dyads (3.09 \pm 0.75 and $2.46 \pm 0.72 \mathrm{~s} / \mathrm{min}$, respectively). Similar differences between dyads were recorded for voiced laughter with same-sex male dyads spending more time laughing than mix-sex and same-sex female dyads ( $2.55 \pm 0.75$ and $2.46 \pm 0.72 \mathrm{~s} / \mathrm{min}$, respectively).

Average laughter rate during humorous segments was 5.4 \pm 3.6 laugh episodes/min and was significantly $(P<0.001)$ higher in same-sex male than in mixed-sex and same-sex female dyads by $1.00 \pm 0.55$ and $0.78 \pm 0.24$ episodes/min, respectively. 


\section{Discussion}

We found that during genuine laughter energy expenditure and HR increased by up to $20 \%$ above resting.

Laughter is a unique human behavior naturally occurring in a variety of social situations. Facial, respiratory and laryngeal muscles are all recruited for laughter production ${ }^{2}$ leading to changes in lung volume and dynamic compression of the airways. ${ }^{15}$ These disturbances of the chest walls and other parts of the body may cause physiological changes requiring increased oxygen consumption leading to a higher HR. Logic suggests that an increase in HR and oxygen consumption should cause an increase in EE. Indeed, participants in our study had 10-20\% higher EE during episodes of laughter than during rest. This increase was dependent on laugh intensity as measured by its duration and rate. Although, to our knowledge, no studies measuring energy cost of laughter have been reported, Boone et al. ${ }^{16}$ in their pilot study with eight college students, have shown a significant increase in stroke volume and cardiac output during viewing a laughter evoking film clip.

To place our data in perspective, we compared these laughter outcomes with some routine daily activities. Sedentary activities such as light clerical work, writing or playing cards can also increase EE by approximately 10-20\%. Other forms of more intense physical activity such as jogging, or household chores can increase EE by $100 \%$ or more. ${ }^{17}$ Energy deficit of $170 \mathrm{~kJ} /$ day could be obtained by walking approximately half to one kilometer. Therefore, although laughter cannot replace exercise or other forms of intense physical activity, its production should not be discounted in the total balance of energy and should be considered a component of the non-exercise activity thermogenesis. ${ }^{18} \mathrm{We}$ have calculated that the energy cost of $15 \mathrm{~min}$ of laughter ranges from 40 to $170 \mathrm{~kJ}$ (10-40 kcal), depending on individual body weight and laughter intensity. This amount of energy expenditure during 1 year, with no changes in other components of energy balance, may translate into an annual weight loss of $0.5-2 \mathrm{~km}$ of body weigh, if all other components of energy balance remained unchanged.

Heart rate during laughter episodes was significantly higher than during rest in our study. There are several reasonable explanations for this increase. Mild exercise inhibits the parasympathetic nervous activity resulting in higher HR. ${ }^{19}$ Moderate or strong exercise activates sympathetic activity with simultaneous withdrawal of parasympathetic nerve activity. ${ }^{20,21}$ It has been shown that laughter has strong but transient effects on the autonomic nervous system ${ }^{22}$ and may contribute to cardioprotection in some personality traits. ${ }^{10}$ In some studies, laughter affected hormonal response, mostly as an effect of increased level of circulating catecholamines. ${ }^{23}$ Levenson ${ }^{24}$ suggested that the association of some emotions with HR change might reflect association with a motor program or action tendency, which makes significant metabolic demands on the heart. Thus, we could assume that similar mechanisms contributed to the increased HR and EE in our participants during the laugh episodes.

Our data must be interpreted with some caution. First, our study was carried out in young adults, which limits the applicability of our results to other age groups. Second, we used a room calorimeter for EE measurements and dyads as measurements units to create a comfortable yet strictly controlled environment. Laughter is far more likely to occur in social situations than in isolation ${ }^{25}$ and is more likely to occur with friends than with strangers. ${ }^{10}$ To ensure adequate laugh production, participants were therefore asked to bring a friend and to participate in dyads. This arrangement most likely reduced anxiety about being in the testing environment. The limitation was that oxygen consumption and carbon dioxide production were measured for dyads rather than individuals. In normal healthy 
adults, however, interindividual differences in resting EE are relatively small. ${ }^{26}$ Small EE measurement errors are inherent but mostly systematic and should not affect the difference between $\mathrm{EE}$ at rest and laughter EE measured in a strictly controlled environment. Furthermore, using an average increase in EE minimized bias caused by the differences in body mass between individuals in a single dyad. Differences in body composition between individuals in dyads did not affect laughter EE (paired $t$-test, $P=0.194$ ).

To ensure that laughter was genuine, participants were unaware that the focus of the study was laughter. They produced various amount of laughter as measured by its duration and rate; both inter- and intra-individual variability was high. Differences between the quartiles sorted by laughter duration shown in Figure 4 illustrate this variability well. A plausible explanation for such variability is that humor appreciation and any resulting laughter depend not only on cognition but other factors such as education, language, semantic, and culture. The level of friendship and social comfort across dyads was unlikely to be equivalent and therefore lead to variability in the laughter duration and rate. It is likely that different social environments (i.e., a comedy show) could facilitate more frequent, longer and more intense laughter episodes and consequently would be more energetically expensive.

In conclusion, genuine voiced laughter causes a 10-20\% increase in energy expenditure and HR above resting values. We calculated that 10-15 min of laughter could increase energy expenditure by $50-170 \mathrm{~kJ}(10-40 \mathrm{kcal})$ per day.

\section{Acknowledgments}

This study was supported partly by the US National Institutes of Health (HBL 001750) to MSB, General Clinical Research Center Grant RR-00095 (to Vanderbilt University) and Clinical Nutrition Research Unit Grant DK-26657 (to Vanderbilt University).

\section{References}

1. Darwin, C. The expression of the emotions in man and animals. In: Ekman, P., editor. Introduction, Afterwards, and Commentaries. 3. Harper Collins (US edit. Oxford University Press); New York: 1998.

2. Ruch, W.; Ekman, P. The expressive pattern of laughter. In: Kaszniak, A., editor. Emotion, Qualia and Consciousness. World Scientific; Tokyo: 2001. p. 426-443.

3. Black DW. Laughter. JAMA. 1984; 252:2995-2998. [PubMed: 6502861]

4. Wild B, Rodden FA, Grodd W, Ruch W. Neural correlates of laughter and humour. Brain. 2003; 126:2121-2138. [PubMed: 12902310]

5. Martin RA. Humor, laughter, and physical health: methodological issues and research findings. Psychol Bull. 2001; 127:504-519. [PubMed: 11439709]

6. Fry W. The physiological effects of humor, mirth, and laughter. JAMA. 1992; 267:1857-1858. [PubMed: 1545471]

7. Bennett MP, Zeller JM, Rosenberg L, McCann J. The effect of mirthful laughter on stress and natural killer cell activity. Altern Ther Health Med. 2003; 9:38-45. [PubMed: 12652882]

8. Hayashi K, Hayashi T, Iwanaga S, Kawai K, Ishii H, Shoji S, et al. Laughter lowered the increase in postprandial blood glucose. Diabetes Care. 2003; 26:1651-1652. [PubMed: 12716853]

9. Kimata H. Elevation of breast milk leptin levels by laughter. Horm Metab Res. 2004; 36:254-256. [PubMed: 15114526]

10. Clark A, Seidler A, Miller M. Inverse association between sense of humor and coronary heart disease. Intern J Cardiol. 2001; 80:87-88.

11. Owren MJ, Bachorowski JA. Reconsidering the evolution of nonlinguistic communication: the case of laughter. J Nonverbal Behavior. 2003; 27:183-200.

12. Sun M, Reed GW, Hill JO. Modification of a whole room indirect calorimeter for measurement of rapid changes in energy expenditure. J Appl Physiol. 1994; 76:2686-2691. [PubMed: 7928901] 
13. Chen KY, Acra SA, Donahue CL, Sun M, Buchowski MS. Efficiency of walking and stepping: relationship to body fatness. Obes Res. 2004; 12:982-989. [PubMed: 15229338]

14. Bachorowski JA, Owren MJ. Sounds of emotion: production and perception of affect-related vocal acoustics. Ann N Y Acad Sci. 2003; 1000:244-265. [PubMed: 14766635]

15. Filippelli M, Pellegrino R, Iandelli I, Misuri G, Rodarte JR, Duranti R, et al. Respiratory dynamics during laughter. J Appl Physiol. 2001; 90:1441-1446. [PubMed: 11247945]

16. Boone T, Hansen S, Erlandson A. Cardiovascular responses to laughter: a inverted question mark pilot project. Appl Nurs Res. 2000; 13:204-208. [PubMed: 11078786]

17. Ainsworth BE, Haskell WL, Whitt MC, Irwin ML, Swartz AM, Strath SJ, et al. Compendium of physical activities: an update of activity codes and MET intensities. Med Sci Sports Exerc. 2000; 9:S498-S516. [PubMed: 10993420]

18. Levine JA, Lanningham-Foster LM, McCrady SK, Krizan AC, Olson LR, Kane PH, et al. Interindividual variation in posture allocation: possible role in human obesity. Science. 2005; 307:584-586. [PubMed: 15681386]

19. Perini R, Veicsteinas A. Heart rate variability and autonomic activity at rest and during exercise in various physiological conditions. Eur J Appl Physiol. 2003; 90:317-325. [PubMed: 13680241]

20. Robinson BF, Epstein SE, Beiser GD, Braunwald E. Control of heart rate by the autonomic nervous system. Circ Res. 1966; 19:400-411. [PubMed: 5914852]

21. Yamamoto Y, Hughson RL, Peterson JC. Autonomic control of heart rate during exercise studied by heart rate variability spectral analysis. J Appl Physiol. 1991; 71:1136-1142. [PubMed: 1757310]

22. Sakuragi S, Sugiyama Y, Takeuchi K. Effects of laughing and weeping on mood and heart rate variability. J Physiol Anthropol Appl Hum Sci. 2002; 21:159-165.

23. Berk LS, Tan SA, Fry WF, Napier BJ, Lee JW, Hubbard RW, et al. Neuroendocrine and stress hormone changes during mirthful laughter. Am J Med Sci. 1989; 298:390-396. [PubMed: 2556917]

24. Levenson RW. Autonomic nervous system differences among emotions. Psychol Sci. 1992; 3:2333.

25. Provine RP, Fischer KR. Laughing, smiling, and talking: relation to sleeping and social context in humans. Ethology. 1989; 83:295-305.

26. Muller MJ, Bosy-Westphal A, Kutzner D, Heller M. Metabolically active components of fat-free mass and resting energy expenditure in humans: recent lessons from imaging technologies. Obes Rev. 2002; 3:113-122. [PubMed: 12120418] 


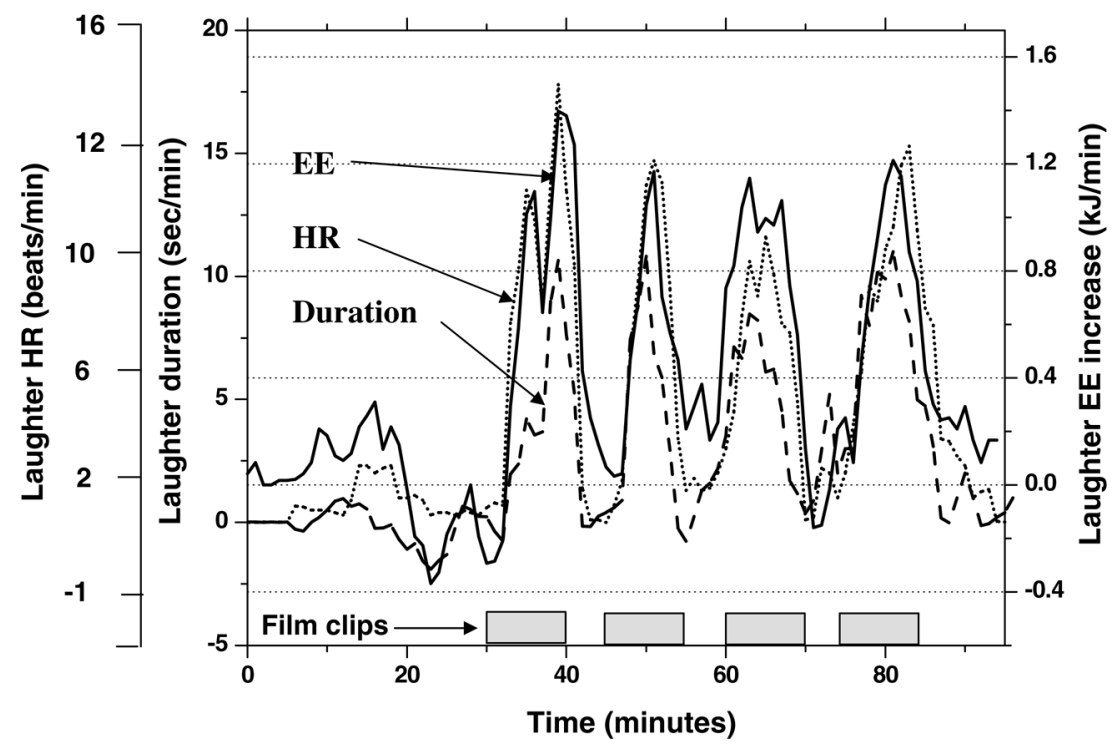

Figure 1.

A sample output of simultaneous measurement of laughter energy expenditure (EE) (Laughter $\mathrm{EE}(\mathrm{kcal} / \mathrm{min})=\mathrm{EE}$ during laugh $-\mathrm{EE}$ at rest), heart rate $(\mathrm{HR}$ (beats $/ \mathrm{min})=\mathrm{HR}$ during laugh - HR during rest), and laughter duration ( $\mathrm{s} / \mathrm{min}$ ) during episodes of laughter evoked by viewing film clips in a male dyad. Periods when humorous film clips were viewed are marked on the time line. 


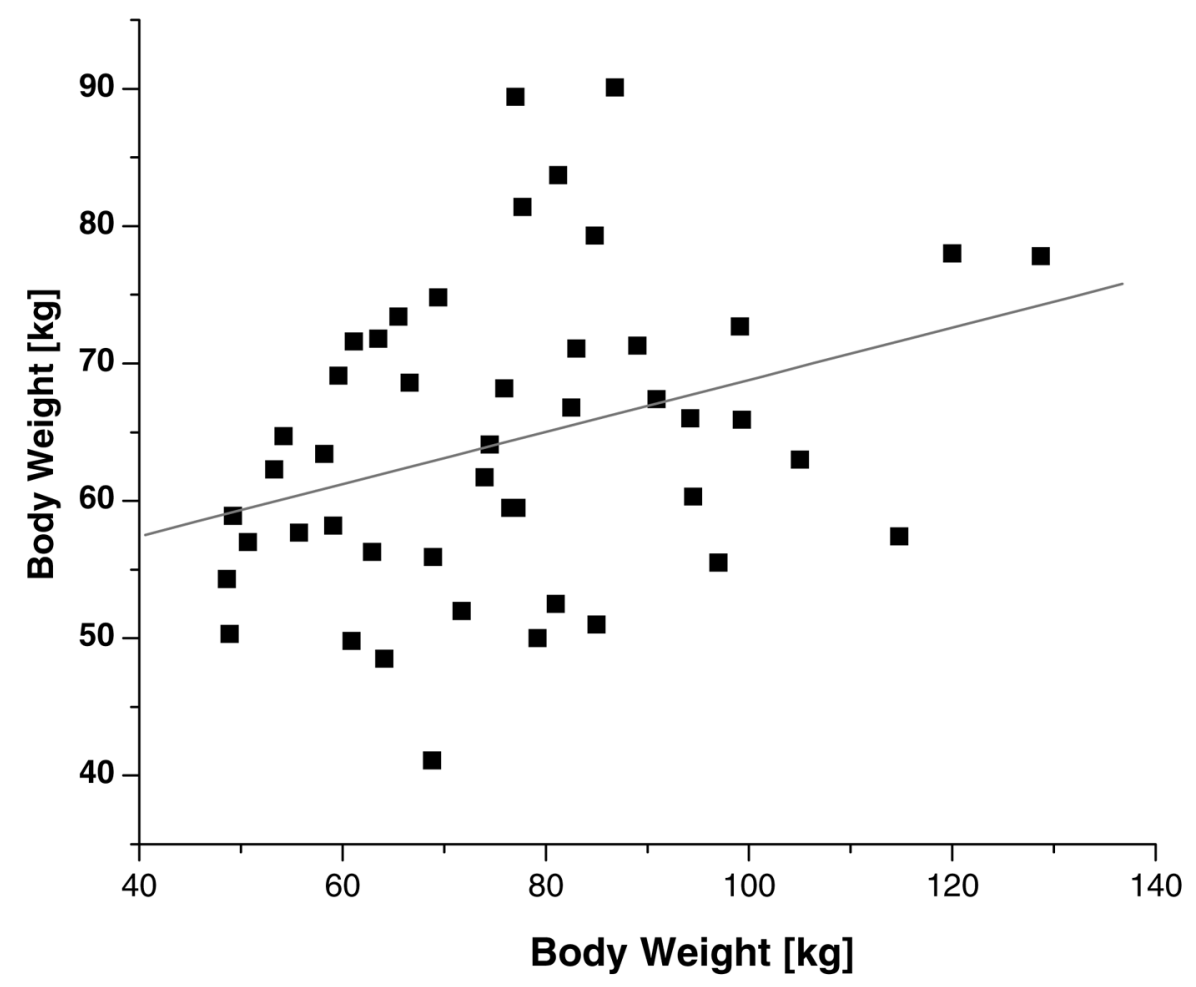

Figure 2.

Body weight $(\mathrm{kg})$ in dyads. Each point represents one dyad. Pearson's correlation between individuals in dyads was significant $(r=0.339, P=0.020)$. 


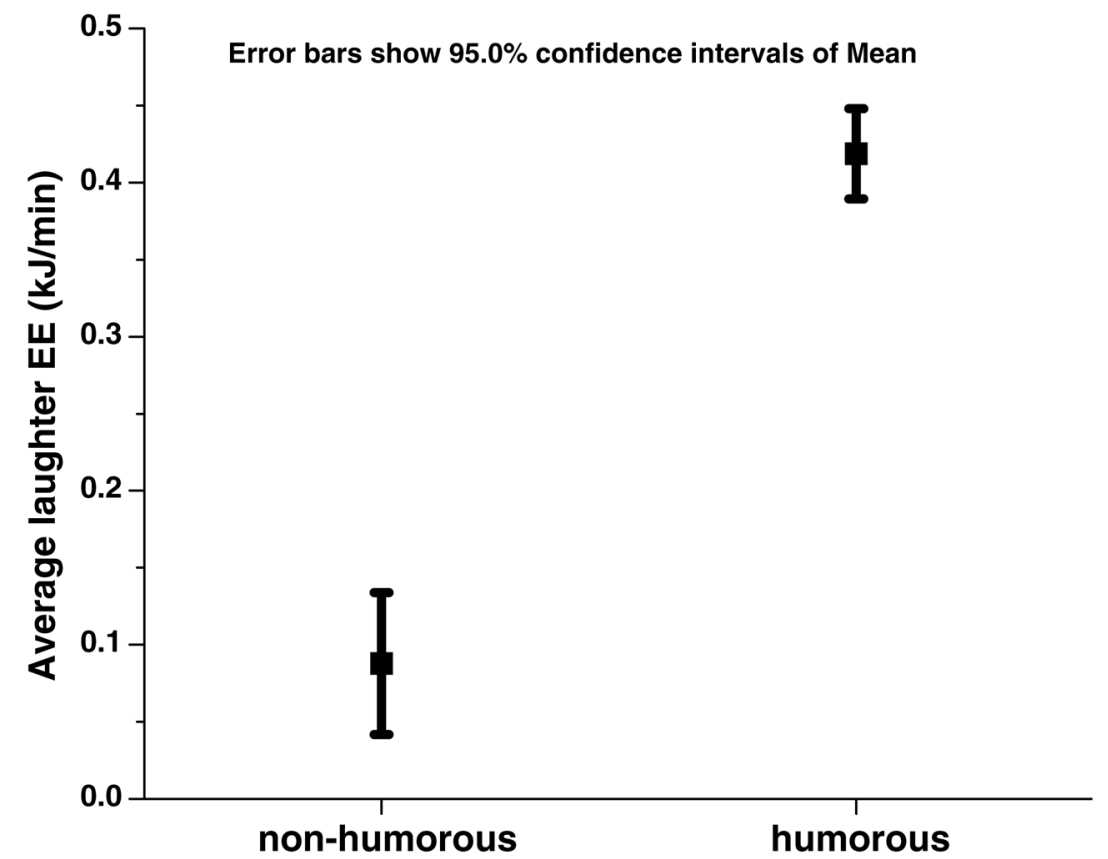

Figure 3.

Laughter energy expenditure (EE) (Laughter EE (kcal/min)=EE during laugh - EE at rest) during viewing film clips unlikely to evoke laughter (non-humorous) and evoking laughter (humorous) in 45 dyads of young adults during 90min session conducted in a whole-room indirect calorimeter. Error bars show 95\% confidence interval of mean. 


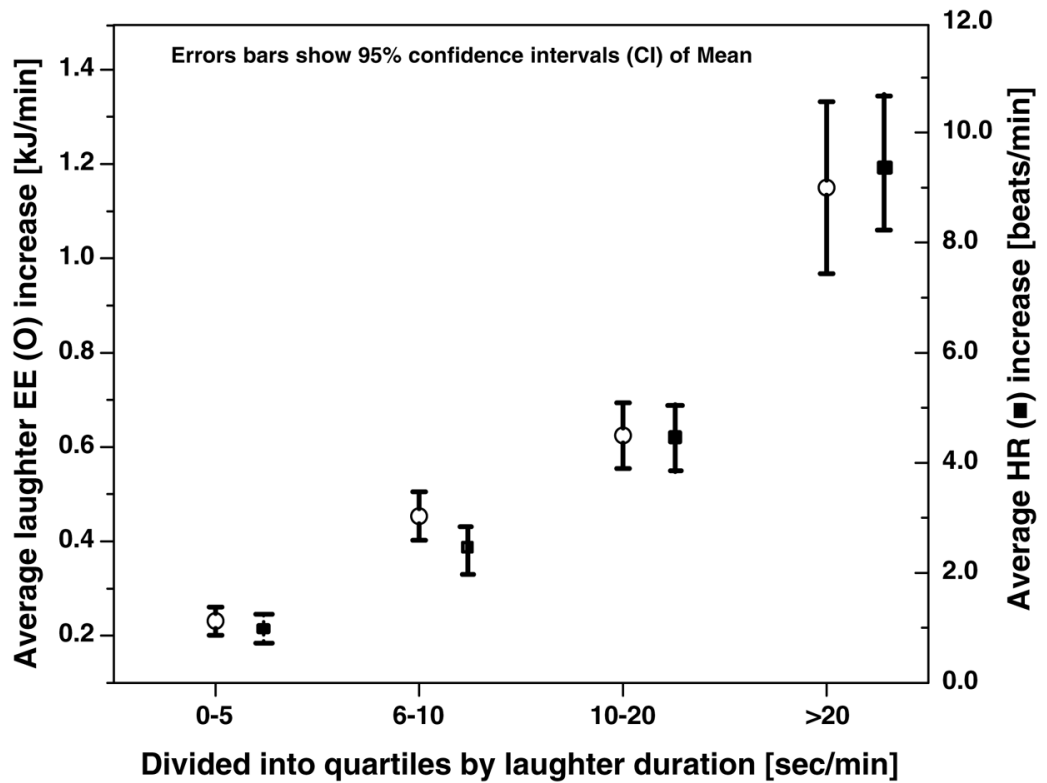

Figure 4.

Laughter energy expenditure (EE) calculated as a difference between EE at rest and during viewing humorous film clips intended to evoke laughter $($ Laughter $\mathrm{EE}(\mathrm{kcal} / \mathrm{min})=\mathrm{EE}$ during laugh - EE at rest) and laughter heart rate (laughter HR) calculated as a difference between $\mathrm{HR}$ at rest and during viewing humorous film clips intended to evoke laughter (Laughter HR (beats/min)=HR during laugh $-\mathrm{HR}$ during rest) divided into quartiles by laughter duration (s/min). 


\section{Table 1}

Subject characteristics ${ }^{a}$

\begin{tabular}{lcc}
\hline & Males $(\boldsymbol{n}=\mathbf{3 1})$ & Females $(\boldsymbol{n}=\mathbf{5 9})$ \\
\hline Body weight $(\mathrm{kg})$ & $84.4 \pm 18.1(59.2-138.7)$ & $62.9 \pm 14.5(41.1-122.7)$ \\
Height $(\mathrm{cm})$ & $178.7 \pm 8.5(150.0-193.0)$ & $165.3 \pm 6.9(150.0-183.0)$ \\
BMI $\left(\mathrm{kg} / \mathrm{m}^{2}\right)$ & $26.4 \pm 4.8(18.8-39.8)$ & $23.0 \pm 4.9(17.0-41.1)$ \\
Age (years) & $22.5 \pm 2.9(18-34)$ & $21.4 \pm 3.4(18-28)$ \\
\hline
\end{tabular}

Abbreviation: BMI, body mass index.

${ }^{a}$ Values are means \pm s.d., values in parentheses are ranges. 


\section{Table 2}

Mean absolute resting energy expenditure (REE), absolute and percentage laughter EE increase (LEE), resting heart rate $(\mathrm{HR})$ and absolute and percentage laughter HR in dyads during rest (30 min) and during viewing film clips selected to evoke laughter $(n=4,40 \mathrm{~min})^{a}$

\begin{tabular}{|c|c|c|c|c|}
\hline & Total $(n=45)$ & Male-male $(n=8)$ & Male-female ( $n=17$ ) & Female-female $(n=20)$ \\
\hline $\begin{array}{l}\text { Resting energy } \\
\text { expenditure }(\mathrm{kJ} / \\
\text { min })\end{array}$ & $1.22 \pm 0.17(0.85-1.66)$ & $1.40 \pm 0.08(1.32-1.66)$ & $1.32 \pm 0.11(1.12-1.53)$ & $1.10 \pm 0.12(0.85-1.37)$ \\
\hline $\begin{array}{l}\text { Laughter energy } \\
\text { expenditure }^{b}(\mathrm{~kJ} / \\
\text { min) }\end{array}$ & $0.414 \pm 0.640(-1.26-4.86)$ & $0.603 \pm 0.816(-1.26-4.86)$ & $0.419 \pm 0.657(-1.17-3.43)$ & $0.356 \pm 0.131(-1.05-3.22)$ \\
\hline$\%$ increase $^{c}$ & $8.14 \pm 12.43(-22.74-80.67)$ & $10.21 \pm 13.85(-22.02-80.67)$ & $7.80 \pm 12.46(-22.74-64.85)$ & $7.78 \pm 11.91(-20.87-59.82)$ \\
\hline $\begin{array}{l}\text { Resting heart rate } \\
\text { (beats/min) }\end{array}$ & $70.79 \pm 6.01(62.46-77.85)$ & $70.79 \pm 6.01(62.46-77.85)$ & $69.88 \pm 7.51(61.56-75.56)$ & $70.76 \pm 7.58(60.45-76.53)$ \\
\hline $\begin{array}{l}\text { Laughter heart } \\
\text { rate }^{d} \text { (beats/min) }\end{array}$ & $2.70 \pm 4.48(-7.61-23.06)$ & $3.23 \pm 4.76(-7.61-23.06)$ & $2.17 \pm 3.97(-6.23-26.77)$ & $2.37 \pm 3.72(-6.85-25.59)$ \\
\hline$\%$ increase $^{e}$ & $3.63 \pm 6.01(-12.74-31.39)$ & $4.85 \pm 7.15(-12.74-42.40)$ & $3.23 \pm 5.98(-8.72-42.40)$ & $3.56 \pm 5.60(-9.93-33.50)$ \\
\hline
\end{tabular}

${ }^{a}$ Values are means \pm s.d., values in parentheses are ranges.

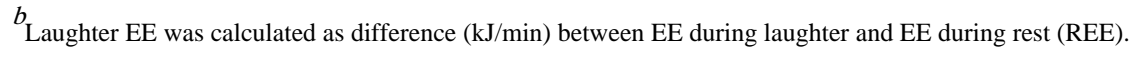

${ }^{c}$ Calculated as \% increase between EE during laughter and EE during rest (REE).

${ }^{d}$ Laughter HR was calculated as difference (beats/min) between HR during laughter and HR during rest (RHR)

${ }^{e}$ Calculated as $\%$ increase between HR during laughter and HR during rest (RHR). 